\title{
A Meta-Analysis of Estimates of Urban Agglomeration Economies*
}

\author{
Patricia C. Melo \\ Daniel J. Graham ${ }^{\dagger}$ \\ Centre for Transport Studies \\ Dept of Civil and Environmental Engineering \\ Imperial College London \\ London SW7 2AZ \\ Robert B. Noland \\ Alan M. Voorhees Transportation Center \\ Edward J. Bloustein School of Planning and Public Policy \\ Rutgers University \\ New Brunswick, NJ 08901
}

\begin{abstract}
Although the productivity gains of urban agglomeration economies are generally found to be positive, there is a great deal of variability in the magnitude of reported estimates. This paper undertakes a quantitative review of the empirical literature on agglomeration through a metaanalysis of 729 elasticities taken from 34 different studies. The objective is to make sense of the range of values for agglomeration economies found in the literature by identifying some key characteristics that affect the magnitude of the results obtained. Our analysis confirms that study characteristics do matter. In particular, we find that country specific effects, the industrial coverage, the specification of agglomeration economies, and the presence of controls for both unobserved cross-sectional heterogeneity and differences in time-variant labor quality can give rise to large differences in the results reported in the literature. In contrast, correcting for reverse causality of agglomeration does not seem to produce noticeable changes in the size of urban agglomeration estimates. We also test for publication bias and find some evidence supporting the presence of positive reporting bias. The findings support the intuition that agglomeration estimates for any particular empirical context may have little relevance elsewhere.
\end{abstract}

JEL Classification: R12, R41.

\footnotetext{
* We would like to thank Henri L. F. de Groot (VU Amsterdam) for helpful comments and suggestions.

${ }^{\dagger}$ Author for correspondence: Centre for Transport Studies, Imperial College London, London SW7 2AZ, UK, Tel: +44 (0)20 7594 6088, Fax: +44 (0)20 7594 6107, Email: d.j.graham@imperial.ac.uk.
} 
Key words: Meta-analysis, agglomeration, productivity, elasticity.

\section{Introduction}

The theory of agglomeration economies proposes that firms enjoy positive externalities from the spatial concentration of economic activities. These benefits can arise from intra- and inter-industry clustering of economic activities, referred to as localization and urbanization economies in the agglomeration literature (see Fujita et al., 1999; and Fujita and Thisse, 2002). This meta-analysis focuses on estimates of productivity gains from urban scale economies, which are thought to arise from improved access to inter-industry information flows, thick labor markets, better access to specialized services, as well as access to general public infrastructure (such as transport and communications) and public facilities (such as hospitals and schools).

Empirical research generally finds positive productivity gains from urban agglomeration, but estimates vary greatly in magnitude. Although there are a number of previous comprehensive reviews of the empirical literature on agglomeration (see Moomaw, 1983b; Gerking, 1994; Eberts and McMillen, 1999; Rosenthal and Strange, 2004), there has been no attempt to quantify the differences in results reported across studies. Rosenthal and Strange (2004) argue that the consensus view of elasticities of urban agglomeration is that doubling urban size increases productivity between 3 to $8 \%$. This claim of a consensus view raises two questions. First, why does there exist a range of magnitude in which the high agglomeration elasticity value is over twice the size of the low value? Second, should we expect to find a reasonably narrow range of consensus at all on elasticities that are derived from different empirical contexts, using different measures of agglomeration, based on different types of data, with different dependent variables and using different empirical economic models? 
The purpose of this paper is to generate evidence that can help provide some answers to these questions. A meta-analysis of the empirical literature on the relationship between urban agglomeration economies and productivity is undertaken to synthesize existing empirical results by means of statistical methods. The principal advantage of meta-analysis lies in the statistical nature of the technique and the consequent ability to minimize subjective bias that could occur in a conventional literature review. Meta-analysis makes explicit the criteria used to judge empirical evidence and allows for the testing of such criteria.

The data used in the meta-analysis includes studies that use either a production function or a wage model to estimate elasticities of urban agglomeration economies. The sample contains 729 elasticity estimates taken from 34 studies that cover the period between 1965 and 2002. Besides summarizing the estimates meta-regressions are estimated to identify systematic sources of variation across empirical results, and the issues of publication bias and within-study dependence are addressed. We find that country specific effects, the industrial coverage, the specification of agglomeration economies, and the presence of controls for both unobserved cross-sectional heterogeneity and differences in time-variant labor quality can give rise to large differences in results reported in the literature. In contrast, correcting for reverse causality of agglomeration does not seem to produce noticeable changes in the size of urban agglomeration estimates.

Our objective in conducting this meta-analysis is to improve the understanding of the range of values for agglomeration economies that are found in the literature by identifying key characteristics that affect the magnitude of the results obtained. By establishing the major determinants of variation in agglomeration estimates found in the literature, we hope our findings can provide a reference point for future research. The results from our analysis can also be used for policymaking aimed at improving regional economic performance through management of city size and densities. In particular, our results could be used in the assessment of the economic benefits 
from urban transport projects. Venables (2007) suggests that there are significant productivity benefits from urban transport improvements that arise through city size, and shows how such effects should be included in the cost-benefit appraisals of transport projects. In some countries, notably the UK, there are guidelines published on how to assess the economic benefits from transport projects. The appraisal of the external benefits of transport improvements is based on the empirical estimates of the elasticity of productivity with respect to city size. Instead of using the estimates from a single study, those seeking to estimate benefits could use the mean from our 729 estimates.

The paper is organized as follows. Section 2 describes the main features of meta-analysis, its advantages and limitations, and explains the criteria used to select the estimates included in the meta-analysis. Section 3 discusses the main characteristics of the literature on urban agglomeration economies and shows how empirical findings vary between different studies. Section 4 sets out key factors that differentiate the literature and thus can be thought to be possible sources of variation in the empirical evidence. In section 5 we present and discuss the meta-regression results. To examine whether reporting bias exists we also perform various tests for the presence of publication bias in section 6 . Section 7 summarizes the main conclusions.

\section{Scope of the Meta-Analysis}

Literature reviews are a fundamental part of the scientific process: they summarize the state of knowledge in the study of a particular topic and identify the remaining important questions requiring additional research efforts. Nonetheless, the process of reviewing empirical literatures can be subjective in the choice of the studies selected, the choice of factors affecting the results, and the interpretation of the results of the studies reviewed. Meta-analysis provides an objective approach to review empirical literature through applied statistical methods that allow testing for the effect of different factors on the empirical results reported in the literature (Stanley and Jarrell, 2005). The 
main objective is to explain the variability across empirical results by estimating the impact of alternative model-design characteristics in the magnitude of empirical results.

Meta-analysis has been applied in psychology and the medical sciences, but to date its use in economics has been sparse, though applications have occurred in the fields of environmental and transport economics and more recently in labor economics (see Ashenfelter et al., 1999; Longhi et al., 2005; Nijkamp and Poot, 2005; Weichselbaumer and Winter-Ebmer, 2005) and international economics (see Rose and Stanley, 2005; de Groot et al., 2005; Disdier and Head, 2008).

Despite its advantages in providing a more objective review of empirical findings, meta-analysis also has estimation difficulties, in particular those arising from publication bias (see Florax, 2001; Stanley, 2005), the choice of the study characteristics thought to affect results, the weighting scheme adopted, and within-study dependence when there are multiple estimates (see Stanley, 2001; Florax, 2002). Publication bias occurs if there is a preference among journal editors and researchers to report statistically significant coefficients that are in agreement with theory. Second, as with any econometric model, the specification of which study characteristics should be included will also affect the results. The estimates included in the meta-sample vary in the use of econometric estimators, country, time period, and degree of spatial aggregation among many other elements. The choice of the study characteristics to be included as meta-regressors is not a clear-cut exercise and is best based upon understanding the key issues within a given literature. Third, if each study is given equal weight regardless of its share in the total number of estimates included in the meta-sample, there is the risk of overweighting smaller studies that contribute only a single estimate and underweighting larger studies that produce multiple estimates. To avoid the unequal weighting of studies some meta-analysts select only one estimate from each study that is identified as a 'best' estimate by the researcher or is selected by the meta-analyst as the more robust result. The main problem with this approach is that it can introduce considerable bias in the meta-analysis. On the 
other hand, keeping all estimates from studies with multiple results also raises issues of withinstudy autocorrelation that can invalidate the results of the meta-analysis.

The first challenge of any meta-analysis is the construction of a valid dataset of comparable empirical estimates. We begin by reviewing the references included in the major empirical surveys of agglomeration economies (i.e. Moomaw, 1983b; Gerking, 1994; Eberts and McMillen, 1999; Rosenthal and Strange, 2004). In addition, we used the ISI Web of Knowledge and Google Scholar to search for papers with keywords such as "agglomeration economies", "urbanization economies", and "urban wage premium". We also used Google to search for additional papers, in particular unpublished works. ${ }^{1}$

It is crucial that the estimates included in the dataset are reasonably comparable. To avoid problems of comparability between estimates from different models our meta-analysis considers only studies that estimate unit-free elasticities. The elasticity estimates included are output elasticities, labor productivity elasticities, and wage elasticities of urban agglomeration. ${ }^{2}$ Besides elasticity values, we also collected the standard errors of the estimates in order to test for publication bias.

There is no standard rule in meta-analysis as to whether single-estimate studies or multiple-estimate studies should be included. We adopt the latter approach. Including all the estimates available allows for efficiency gains from increased sample size and permits examining within-study variation across elasticity estimates. ${ }^{3}$ The main disadvantages of using multiple-estimate studies consist of a possibly less representative sample and inconsistent OLS estimators since observations

\footnotetext{
1 The closing date for the search of studies was October 2008.

${ }^{2}$ Urban agglomeration elasticities are derived from population and employment-based measures of urban size, rather than measures of diversity of economic activity.

${ }^{3}$ Koetse, Florax and de Groot, (2007) show that small increases in the meta-sample size produce substantial improvements in the estimators. Such findings reinforce our choice to increase the meta-sample by including all estimates from studies with multiple estimates.
} 
from the same study are not likely to be independent. The sample consists of 729 estimates taken from 34 studies. $^{4}$

\section{Overview of the Literature}

This section describes the main characteristics that distinguish studies estimating agglomeration economies and demonstrates that there is variation in the empirical findings. We structure this review around the main estimation issues in the literature, in part because these provide some of the key dimensions we wish to test in the meta-regression analysis.

The standard approach to estimate the impact of agglomeration externalities on economic output uses a production function framework. A general specification can be given by:

$Y_{i t}=G_{i t}() F.\left(X_{i t}\right)$

Equation 1

where $Y$ is the private output in area $i$ at time $t$ and is composed of a technology function, $F(X)$, which gives the combination of input factors $X$, and a shift term, $G($.$) , which contains some$ representation of agglomeration economies. Within this framework, agglomeration economies can improve economic output indirectly by raising the marginal productivity of the private input factors $X$. Another common estimation approach uses wage equations. Wage equations can be derived directly from a production function by assuming that factor prices represent the value of the marginal products (see Combes et al., 2008b). Some other researchers use a Mincerian type wage

\footnotetext{
${ }^{4}$ There is no standard value for a minimum acceptable meta-sample size. Other meta-analyses with similar sizes include Nitsch, (2005) with 29 studies on Zipf's law of cities; Nijkamp and Poot, (2005) with 17 wage curve studies; Wieser, (2005) with 17 firm level studies of the rate of return to research and development; Longhi, Nijkamp and Poot, (2005) with 18 studies for the elasticity of wages with respect to the ratio of immigrants over native workers; Jeppesen, List and Folmer, (2002) with 11 studies on the relationship between new plant location and environmental regulations; Gorg H., (2001) with 21 studies estimating productivity spillovers of multinational companies; Button, (1998) with 26 studies estimating output elasticities with respect to public infrastructure investment; and Stanley, (1998) with 28 studies of the Ricardian equivalence theorem.
} 
equation (Mincer, 1974) where the wage of worker $i$ in location $j$ is explained by a set of workerspecific variables (education, age, etc.) and a set of location-specific characteristics among which is some measure of urban agglomeration economies.

Previous research that has estimated agglomeration economies has concentrated on the relative importance of localization and urbanization economies, that is, whether agglomeration economies arise from industrial concentration or from city size. These studies test the role of agglomeration either through separate measures of localization and urbanization, or through simultaneous estimation of the two effects. Studies incorporating both measures tend to find stronger localization effects (e.g. Henderson, 1986; Henderson, 2003), whereas urbanization economies are generally more important for light industries (Sveikauskas et al., 1988; Nakamura, 1985) and knowledge intensive services such as finance, insurance, and real estate (see Duranton and Puga, 2000).

Early studies estimate production functions using cross-sectional aggregate regional data or data for some aggregated industries, generally manufacturing (e.g. Aberg, 1973; Sveikauskas, 1975; Moomaw, 1981; Moomaw, 1983a; Moomaw, 1985; Nakamura, 1985; Henderson, 1986; Sveikauskas et al., 1988). More recent studies increasingly make use of disaggregated data for various time periods. Examples include studies using firm/worker level data to estimate production/wage functions (e.g. Wheeler, 2001; Henderson, 2003; Mion and Naticchioni, 2005; Graham, 2007a; Graham, 2007b; Graham, 2007c; Graham and Kim, 2008; Combes et al., 2008a; Combes et al., 2008b; Rosenthal and Strange, 2008). The advantages of micro level data are that they can better represent firm optimizing behavior that we assume from economic theory, provide greater data variability, and can reduce multicollinearity and aggregation bias resulting from unobserved heterogeneity (Griliches and Mairesse, 1995). 
Another source of differences between studies concerns the measurement of urban agglomeration. The initial and common approach was to represent urban scale economies through measures of total urban concentration, such as total urban population (e.g. Aberg, 1973; Sveikauskas, 1975; Moomaw, 1981; Moomaw, 1983a; Moomaw, 1985; Nakamura, 1985; Sveikauskas et al., 1988). Ciccone and Hall (1996) introduced the use of employment density. The main advantages of employment density are twofold: first, they can better capture the productivity benefits of spatially concentrated economic activities, whereas total population in a given area will also proxy for urban amenities and potential congestion costs; secondly, density-based measures are robust to differences in land area sizes. The main limitation, as with total population, is the assumption that the effects from agglomeration economies are confined to the boundaries of the geographic units used. To account for possible spatial spillovers from agglomeration effects more recent studies have adopted a "market potential" type measure of agglomeration economies that is not restricted to geographic boundaries, and allows the effects of agglomeration externalities to be realized over space and diminish with increased distance. While some studies adopt a distance-unrestricted market potential measure (e.g. Graham, 2007a; Graham, 2007c; Graham and Kim, 2008), others separate the distance-unrestricted market potential function into a set of successive distance-band measures (e.g. Rice et al., 2006; Rosenthal and Strange, 2008).

The presence of reverse causality between productivity and agglomeration makes the estimation of the impact of agglomeration on productivity a difficult task. Most of the empirical research assumes that causality runs from agglomeration to productivity. This is consistent with standard urban economic theory. Some studies, however, have allowed agglomeration to be simultaneously determined with productivity. The rationale is that firms and workers migrate to more productive areas and increase their size and density. To correct for the endogeneity of agglomeration economies studies have experimented with instrumentation techniques. The most common strategy is to use long-lagged values of population or population density to instrument present values of 
agglomeration economies (Ciccone and Hall, 1996; Mion and Naticchioni, 2005; Rice et al., 2006; Combes et al., 2008a; Combes et al., 2008b) and geographical instruments (Ciccone, 2002; Rosenthal and Strange, 2008; Combes et al., 2008b). The motivation for the choice of these instruments is that both past levels of urban size and external geologic variables (land area, proportion of area covered by water, seismic hazard, etc.) are correlated with current levels of urban size but not with current levels of productivity.

The quality of the labor force can also be endogenous. Human capital is a key variable in determining the level of productivity as defined in new growth theories. In the framework of the estimation of agglomeration economies, the positive effect of urban size (density) may result from the stronger presence of a skilled labor force in denser areas. Thus, the effect of density may not reflect a true agglomeration economy but instead a higher level of human capital.

Table 1 lists the studies included in the meta-analysis. It shows the number of estimates taken from each study, the period of analysis of the study, the type of data used, the industrial coverage, the mean elasticity estimate, and the range of estimated elasticity values. The sample includes elasticities of urban agglomeration that cover more than three decades, between 1965 and 2002. There is a predominance of estimates for the manufacturing sector. The use of panel data has increased over time and seems to be associated with a greater number of estimates per study. Since the number of effect sizes varies across studies, we perform a test for the equality of means by excluding studies one-by-one from the full sample. The null of equality between full sample and reduced sample means is not rejected for any of the 34 subsamples, suggesting weak sensitivity to the omission of a particular study.

Table 2 reports unweighted averages of the individual estimates and studies. Estimates vary between -0.800 and 0.658 with mean 0.058 and standard deviation 0.115 . The 5th and 95th 
percentiles are -0.090 and 0.292 , and the interquartile range is 0.068 , suggesting a great deal of variation in the estimated urban elasticities. For the study-averaged estimates, the values vary between -0.088 and 0.194 . Further summary statistics are provided based on various dimensions of study-design such as the country of analysis, the measure of urban agglomeration economies, the industrial coverage, and dependent variable. The effect of urban agglomeration appears to be substantially stronger for service industries than for manufacturing. Estimates obtained from models using a market potential type measure appear to have higher elasticities of urban economies than studies using measures of total urban size and employment density. Moreover, wage elasticities of urban agglomeration appear to be on average smaller than labor productivity elasticities.

[Insert Table 1]

[Insert Table 2]

Figure 1 depicts the variation of the estimated elasticities of urban agglomeration economies over the time period of the studies. Time periods are measured as the midpoint if the data are for more than one year. We observe that there are many more estimates that use data from more recent periods, in particular after the early 1980s. Along with the increase in the number of estimated parameters there is also an increase in the range of elasticity values to include larger positive estimates but also some negative estimates. The average elasticity estimate for the studies with a midpoint between 1965 and 1969 is 0.055 , while for the periods between 1970 and 1979, and 1980 and 1989 the average elasticities are 0.026 and 0.042 respectively. The average elasticity for the period after 1990 is 0.081 .

[Insert Figure 1] 


\section{Variables in the Meta-Regressions}

To identify the sources of systematic variation across the effect sizes, we perform meta-regressions that control for differences in study design characteristics. There is no guidance on which explanatory variables one should use; however, there are various study design characteristics that the literature indicates may have an impact on the size of urban agglomeration elasticities. To establish the contribution of different causes of variation in the estimated elasticities we define a range of meta-explanatory variables.

First, we include variables that account for the nature of the data used in different studies. To control for differences in the time periods we include a set of time dummies. The motivation for distinguishing between different time periods is that we want to examine whether the returns to urban agglomeration economies have persisted, increased or declined over time. This is of particular interest since it can provide some insight on how the tendency of reduced transport costs and the use of information and communication technologies (ICT) may have affected the size of the returns to spatial agglomeration. A positive relationship between improved communication technologies and urban agglomeration economies have been found by Shefer (1988), Shefer and Bar-El (1993), and Gaspar and Glaeser (1998). The reference case includes the estimates of the elasticity of urbanization economies obtained using data for the 1960s.

The estimates of the elasticity of urbanization economies also differ with respect to country, economic sector, whether the data is cross-sectional or panel data, the level of aggregation, and the type of geographic units used. These differences are likely to influence the size of the elasticity of urbanization economies. Countries are generally distinct in terms of the urban planning policies that determine the form and size of their urban systems. One possible consequence is that cities will vary not only in size but also in the way they are organized to support their scale; the availability of 
efficient transport infrastructure and other public facilities will affect the size of the returns to urban scale. To account for these differences we include a set of controls for each individual country. Because some studies use multiple-country data (Ciccone, 2002 and Brulhart and Mathys, 2008 estimate models for NUTS regions in Europe), we also use a set of controls for country groupings. More precisely, we use country-level dummy variables for the sample with only single-country studies; the reference case includes the estimates of the elasticity of urbanization economies obtained for the US. In the sample with both single- and multiple-country estimates we specify a dummy variable that distinguishes between different continents. The reference case includes the estimates of the elasticity of urbanization economies obtained for European countries.

Glaeser and Kohlhase (2004) show evidence that services tend to be located in dense areas because they are more dependent on proximity to costumers than manufacturing industries. To test for differences in the size of urban agglomeration effects across economic sectors we include a dummy variable that controls for the economic sector of the elasticity estimates. The reference case includes the estimates of the elasticity of urbanization economies for the entire aggregate economy. Combes et al. (2008a) find that there is positive aggregation bias from using regional instead of worker level data. To test for the impact of using firm/worker individual data on the size of agglomeration effects we include a dummy variable that equals 1 if the study uses micro level data and 0 if regional level data is used instead. We also control for the use of panel data as opposed to cross-sectional data, where the latter is the reference case.

To investigate whether the strategy of measurement of urban agglomeration influences the size of the elasticity estimate we define a set of control variables that distinguish between the use of measures of total size (population/employment) in contrast to measures of employment density, and measures based on market potential or distance bands. Because distance band measures are essentially a sum of successive distance-restricted market potential measures we use the same 
control variable for the two; to have comparable estimates, we sum each distance band-specific elasticity estimate over the distance intervals used. The reference case consists of the elasticities of urbanization economies obtained from measures of total size.

Similarly, the type of geographic unit can also be a potential source of variation in the empirical estimates. Since economic data are often more available for administrative divisions than for geographic units with more economic meaning, it is common to find estimates of agglomeration based on administrative spatial units. Administrative boundaries, however, can be less appropriate to capture the spatial scale of agglomeration effects. As an alternative to administrative definitions, some studies base their measures of agglomeration on geographic areas that can better mirror the economic process underlying agglomeration economies. Examples include the use of employment areas in France, local labor markets in Italy, and metropolitan statistical areas in the US. These areas are typically related to the scale of labor markets and contain a large part of the interactions through which agglomeration effects are determined, in particular those arising from labor market pooling and knowledge spillovers (Combes et al., 2008a; Combes et al., 2008b). To investigate whether differences in the type of geographic units used influence the size of the elasticity of urbanization economies, we include a control variable that takes value 1 if the study uses economically meaningful geographic units and 0 if it uses administrative boundaries.

The choice of estimation technique is also important because it determines the extent to which studies correct for issues of omitted variables and endogeneity bias. We test for the effect of correcting for endogeneity of reverse causality between productivity and agglomeration through the use of instrumental variables estimators. The reference case includes the estimates of the elasticity of urbanization economies obtained from studies that do not correct for reverse causality. The use of cross-sectional fixed-effects can minimize the problem of the endogeneity of labor quality (see Combes et al., 2008a; Combes et al., 2008b) because it controls for (cross-sectional) unobserved 
heterogeneity that may be correlated with urbanization economies (e.g. unobserved managerial and worker skills). To test for the role of fixed-effects on the size of the estimates we include a dummy variable that takes value 0 if studies do not use cross-sectional fixed-effects.

We also test for the effect of controlling for other possible sources of agglomeration. In particular, we want to test for omitted variable bias resulting from the omission of a measure of localization economies. Some studies include urbanization and localization economies simultaneously in their models, while others include only urbanization economies. Because the two tend to be positively correlated we would expect to find higher elasticities of urbanization economies when localization is not included in the model. The reference case includes the estimates of the elasticity of urbanization economies obtained from studies that do not include a measure for localization economies. Similarly, failing to control for the time-variant quality of the labor force is likely to produce the same upward bias outcome since the level of human capital tends to be positively associated with urban size. To test this hypothesis we include a dummy variable that identifies if the study controls for human capital heterogeneity; the reference case includes the studies that do not control for differences in human capital.

Finally, to distinguish between production and wage models we use a dummy variable to control for the type of response variable used (total output, labor productivity, or wages). The reference case includes the estimates of the elasticity of urbanization economies obtained from studies that use output as the dependent variable. The meta-independent variables are listed and summarized in Table 3

[Insert Table 3] 


\section{Results}

We now report results from the meta-regressions. Because we use multiple-estimates per study, observations from the same study can be correlated. To deal with within-study dependence of the elasticity estimates we use a static panel data framework formulated as a cluster-specific randomeffects model. Previous meta-analyses using this specification include Jeppesen et al. (2002), Nitsch (2005), and Disdier and Head (2008).

We start with a simple OLS model. The meta-regression can be written as follows:

$\hat{\varepsilon}_{i}=\varepsilon_{0}+\sum_{j=1}^{J} \beta_{j} D_{j i}+\mu_{i}$

Equation 2

Where $D_{j i}$ is a dummy variable for the meta-independent variable $j(j=1,2, \ldots, J)$ and estimate point $i$ $(i=1,2, \ldots, N), \beta_{j}$ gives the impact of study attribute $j$ on the effect size, and $\mu_{i}$ is the error term. The specification for the static panel data random-effects approach can be written as below:

$\hat{\varepsilon}_{i g}=\varepsilon_{0}+\sum_{j=1}^{J} \beta_{j} D_{j i}+\delta_{g}+\mu_{i g}$

Equation 3

where $i$ denotes the elasticity estimate, $g$ identifies the group (study), $\delta_{g}$ is the study random-effect that controls for paper-specific effects that are common to all individual estimates from the same study, and $\mu_{i g}$ is the normal white noise residual term.

The results for the OLS and random-effects models are reported in Table 4. Models (1) to (4) report the estimates for the full sample (including estimates from production functions and wage models), whereas models (5) to (8) present the results for the sample containing only production function 
estimates. Models (1), (3), (5), and (7) provide the results for the specification using individual country dummy variables while models (2), (4), (6) and (8) report the results for the specification using groupings by continent. ${ }^{5}$ The goodness of fit statistics are also reported in the table. For the panel models, the high between $\mathrm{R}^{2}$ indicates that the main source of explanatory variation is between, not within, studies. The Breusch and Pagan Lagrange Multiplier (LM) test for random effects with null hypothesis $\operatorname{Var}\left(\delta_{\mathrm{g}}\right)=0$ failed to be rejected, suggesting that random-effects are not needed and the pooled OLS model is appropriate. ${ }^{6}$

We consider first the models for the full sample: models (1) to (4). The coefficients on the time periods imply that the effects of urban agglomeration on productivity have generally not significantly changed over time with the exception of the 1970s, for which there is some evidence of smaller elasticity values (about 3 to 4 percentage points ${ }^{7}$ ) in comparison to the reference period (1960s). There are 158 elasticity estimates (5 studies) in our meta-sample that are based on data from the 1970s; the elasticity values range between -0.37 and 0.27 and have a mean of 0.03 . These estimates are based primarily on US data (100 out of the 158 estimates); Brazil and Japan account for 20 and 38 estimates each. Further inspection of the literature allowed us to find comments drawing on the relationship between the loss of urban population and decentralization of manufacturing to smaller cities in the 1970s and the decline in productivity levels, particularly in the US (Moomaw, 1981; Eberts and McMillen, 1999).

The coefficients of the individual country and continent dummy variables indicate that country/regional differences explain differences in the magnitude of the returns to urban agglomeration. To the extent that countries differ in their urban and regional planning policies we

\footnotetext{
${ }^{5}$ We also experimented with a control variable that distinguishes between developing and developed countries and found similar results to those reported here. The problem with this classification is that it changes over time since developing economies eventually become developed economies.

${ }^{6}$ Based on Stata's $x$ ttest 0 command.

${ }^{7}$ The coefficients of the meta-regressions measure the deviation (in percentage points) from the elasticity value predicted by the models, which is about 0.06 . A coefficient of -0.03 therefore corresponds to a percentage decrease in the elasticity value of about $50 \%$.
} 
can expect that some of the variation in the size of the returns to urban size will be picked up by the country/region-specific effects. Our results suggest that China, Japan, and Sweden tend to exhibit smaller estimates of urban agglomeration elasticities than the US, whereas France and Italy seem to have higher values. There can be a variety of factors explaining these differences. Au and Henderson (2006), for example, find that migration restrictions in China have resulted in many undersized cities and consequent losses in net output per worker. The coefficients for the continent dummys suggest higher effect sizes for countries in South America (Brazil), and smaller effects for North America (US and Canada).

The results show that service industries tend to derive considerably larger benefits from urban agglomeration. The size of the elasticity of urban agglomeration for service industries is about 8 percentage points higher than the size of the elasticity estimates for the aggregate economy. On the other hand, there is no noticeable difference between the size of the urbanization estimates for manufacturing industries and the whole economy. This result is consistent with our hypothesis that service industries tend to be more dependent on proximity to large urban areas, whereas manufacturing industries have generally undertaken a process of decentralization to the outskirts of big cities or moved to smaller cities.

There is some significant evidence suggesting that the use of panel data can reduce the size of the elasticity estimates by roughly 3 percentage points. As for the effect of using individual level (firm or worker) data, there appears to be no noticeable effect compared to the use of aggregated regional data. The effect of using different types of geographic units appears not to be significant in the sample with single-country estimates, whereas it appears to have a positive effect on the size of the elasticity for the sample with cross-country estimates. ${ }^{8}$ Having inspected the data it seems that the sign reversal could arise from the addition of negative 'outlier' values for the elasticity estimates in

\footnotetext{
${ }^{8}$ Using a different methodology, Briant et al. (2008) also test whether the use of spatial units of different size and shape affects the magnitude of agglomeration estimates. They conclude that differences in the size and shape of spatial units have minor effects on the magnitude of agglomeration estimates.
} 
the cross-country studies. Brulhart and Mathys (2008) report elasticity estimates across a broad range, from -0.80 to 0.30 , with an average elasticity of -0.08 . Since these studies all use administrative spatial units their inclusion in the sample effectively raises the average elasticity estimate obtained from “economic” spatial units.

The controls for the econometric design suggest that using cross-sectional fixed-effects to control for time-invariant cross-sectional unobserved heterogeneity tends to reduce the size of the elasticity of urbanization by roughly 2 percentage points. In contrast, correcting for reverse causality between agglomeration and productivity appears not to produce a statistical difference in the size of the elasticities of urban agglomeration.

We also evaluate the impact of measuring urban agglomeration with employment density and market potential type variables instead of total urban size. Coefficients for both are statistically not different from zero. The parameters of the controls for the inclusion of localization economies and measures of the quality of the labor force suggest that these variables constitute an important source of variation across the estimates; their omission tends to produce positive upward bias. Including a measure for localization appears to reduce urbanization estimates by about 2.5 percentage points, while controlling for differences in the level of time-variant human capital reduces the estimates by about 5 to 6 percentage points. Finally, we observe that there is no significant effect on the size of the elasticity estimates from using wages or labor productivity as the dependent variable.

We now consider the results for the sample containing only elasticity estimates from production functions. Overall, the findings conform to those identified for the full sample, both with respect to statistical significance and magnitude. The key findings can be summarized as follows. We find larger elasticity values for service industries, positive omitted variable bias resulting from the failure to control for differences in human capital levels across cross-sectional units and the 
omission of measures for localization economies. There is also some evidence suggesting that the use of panel data can produce lower estimates of urban agglomeration. As for the effect of the type of spatial unit, it appears to be negative for the sample with single countries but positive for the sample with both single- and cross-country estimates.

[Insert Table 4]

\section{Publication bias}

Another important issue that should be considered in any meta-analysis is that of publication bias. Theoretically, the literature on agglomeration economies suggests a positive relationship between urban size and productivity. This can have two potential implications for the publication process. First, reviewers may be more favorable when significant and positive elasticities of urbanization economies are found. Second, researchers may filter their own work and choose to present only statistically significant and positive estimates. The outcome is a preference to report significant and positive elasticity estimates. To reduce the influence of reporting bias, the meta-sample can also include unpublished studies. However, this addition in scope might not be sufficient to correct for potential reporting bias because authors can censor their own work to report only estimates in accordance with theory, and because unpublished works sometimes eventually become published articles.

To investigate the presence of publication bias we look at the relationship between the elasticity values and their standard errors, as suggested by previous meta-analysis studies (see Card and Krueger, 1995; Gorg and Strobl, 2001; Stanley, 2005; Disdier and Head, 2008). If there is a preference to report significant estimates we expect to see a positive association between the size of the elasticity estimates and their respective estimation errors (given by the standard errors), so that 
the absolute value of the $t$-statistic is at least about 2 . On the other hand, if there is no reporting bias we expect to find a random association between the two variables. Papers that do not report standard errors are excluded from this analysis. In addition, we follow Card and Krueger's (1995) and Disdier and Head's (2008) approach and limit our sample to include only the "favorite" estimates reported in the different studies. Because not all papers explicitly identify their most preferred estimates, we select the elasticity estimates associated with higher $\mathrm{R}^{2}$ values. As a result, our sample is reduced to 27 papers, 22 of which are published in journals. Note that there can be more than one "favorite" estimate per paper: a study that estimates agglomeration economies for separate economic sectors can have one preferred estimate for each economic sector. ${ }^{9}$

Figure 2 shows the relationship between the elasticity estimates and their respective standard errors. The coefficient of correlation between the elasticity values and respective standard errors is -0.04 for the papers published in journals and 0.94 for those not published. The apparent weak relationship between the estimates from studies published in journals and their standard errors results from the inclusion of both the positive and the negative elasticities in the same plot. The appropriate approach should consider the relationship between the absolute values of the elasticity estimates and their respective standard errors, as shown in Figure 3. The correlation between the absolute value of elasticity estimates and their standard errors for the papers published in journals becomes much stronger (0.28). Figure 3 also shows the line that corresponds to values of the tstatistics of the elasticity estimates equal to 2 . We observe that many of the elasticity estimates are above the line corresponding to the standard threshold for statistical significance, suggesting that there is some evidence of publication bias.

[Insert Figure 2]

[Insert Figure 3]

\footnotetext{
${ }^{9}$ There are 29 papers that report standard errors, but we could only identify a "preferred” elasticity estimate for 27 papers.
} 
To formally test for publication bias we estimate some regressions. We can specify the relationship between the elasticity estimates and their respective standard errors through the model below:

$\hat{\varepsilon}_{i}=\varepsilon_{0}+\alpha \operatorname{se}(\hat{\varepsilon})_{i}+\mu_{i}$

Equation 4

where $\hat{\varepsilon}_{\mathrm{i}}$ is the estimated effect size, and $\operatorname{se}(\hat{\varepsilon})_{i}$ is the standard error of the elasticity estimate, which is included to capture the presence of reporting bias (Knell and Stix, 2005; Stanley, 2005; Rose and Stanley, 2005). Additionally, we test for the presence of publication bias independently of its direction, as specified by the following equation (Stanley, 2005).

$\left|\hat{\varepsilon}_{i}\right|=\varepsilon_{0}+\alpha \operatorname{se}(\hat{\varepsilon})_{i}+\mu_{i}$

Equation 5

If we accept the null that $\alpha=0$ there is no systematic relationship between the elasticity values and their standard errors and hence we can conclude there is no publication bias. Finally, we estimate a more flexible model that allows for positive and negative directional reporting bias.

$\hat{\varepsilon}_{i}=\varepsilon_{0}+\alpha_{p i} D_{p i} \operatorname{se}(\hat{\varepsilon})_{i}+\alpha_{n i} D_{n i} \operatorname{se}(\hat{\varepsilon})_{i}+\mu_{i}$

Equation 6

where $D_{p i}$ is a dummy variable which takes value 1 if $\hat{\varepsilon}_{i}>0$ and $D_{n i}$ takes value 1 if $\hat{\varepsilon}_{i}<0 .{ }^{10}$ Table 5 reports the results of equations 4 to 6 under models (1), (2), and (3), respectively.

As expected from the discussion on Figure 2 and Figure 3, the small $\alpha$ coefficient in model (1) fails to be statistically different from zero. However, if we consider the total size of the potential reporting bias, through a regression of the absolute values of the parameter estimates on their

${ }^{10}$ We follow Bom and Ligthart, (2007) for this approach. 
standard errors, we find evidence suggestive of publication bias: the slope of the regression is 0.22 with a standard error of 0.09 . While model (2) suggests there is reporting bias, model (3) considers the direction of the bias by testing for a symmetric effect between positive and negative reporting bias. The rejection of the null of symmetric reporting bias in model (3) suggests there is positive asymmetry. Our results suggest that those values that are published tend to emphasize larger positive effects.

Card and Krueger (1995) propose an alternative test of publication bias that examines the relationship between the absolute value of the t-statistics and the size of the study's sample, or equivalently its degrees of freedom. This test basically consists of assessing the statistical significance of the coefficient of the regression of the log of the absolute value of the t-statistics and the log of the square root of the degrees of freedom of the studies. If the coefficient can not be rejected to be statistically different from 1 , there is no evidence of publication bias. Unfortunately, we only have 20 papers that report both standard errors and sample sizes. To implement a similar test we regress the log of the absolute value of the t-statistic and the log of the square root of the sample size. The coefficient obtained is 0.25 and we reject the hypothesis that it is equal to 1 , suggesting publication bias.

[Insert Table 5]

\section{Conclusions}

This paper reports results from a meta-analysis designed to examine the variation in empirical estimates of the effect of urban agglomeration on productivity. The analysis includes 729 estimates taken from 34 studies that differ in the use of estimation method, time period, country of study, level of spatial and industrial aggregation, and definition of agglomeration economies. We use 
regression analysis to distinguish the contribution of different study characteristics to the variance of estimates.

The results show that study characteristics do matter. We find that country specific effects, industrial coverage, the specification of agglomeration economies, and accounting for both the endogeneity of labor force quality and unobserved cross-sectional heterogeneity in time-variant labor quality can give rise to large differences in the results reported in the literature. We also test for the possibility of publication bias and find there is some evidence supporting the presence of positive reporting bias in agglomeration estimates.

These results provide guidance for future research in this area. Of particular importance is the need to consider the results of agglomeration estimates in context and that there is no a priori reason to expect similar estimates of comparable magnitude between sectors, urban areas, or countries. Another finding is that explicit treatment of the endogeneity of agglomeration economies appears not to produce any significant changes, leading us to conclude that endogeneity bias of agglomeration may not be a major concern. A renewed focus on the service sector is also clearly required. While historically agglomeration of manufacturing was of interest, the larger potential benefits of service sector agglomeration deserve further study. Finally, our finding of publication bias suggests the need to not discount negative findings. Reviewers, editors, and authors must be more willing to accept that non-significant findings increase our knowledge of the fundamental theories as much as statistically significant findings, and in some cases, perhaps more so.

\section{Appendix A: List of studies included in the meta-analysis}

ABERG, Y. (1973) Regional productivity differences in Swedish manufacturing. Regional and Urban Economics, 3, 131-155. 
AU, C. C. \& HENDERSON, J. V. (2006) Are Chinese cities too small? The Review of Economic Studies, 73, 549.

BALDWIN, J. R., BECKSTEAD, D., BROWN, W. M. \& RIGBY, D. L. (2007) Urban economies and productivity. Economic Analysis (EA) Research Paper Series.

BALDWIN, J. R., BROWN, W. M. \& RIGBY, D. L. (2008) Agglomeration economies: microdata panel estimates from Canadian manufacturing. Economic Analysis (EA) Research Paper Series.

BRÜLHART, M. \& MATHYS, N. A. (2008) Sectoral agglomeration economies in a panel of European regions. Regional Science and Urban Economics, 38, 348-362.

CICCONE, A. \& HALL, R. E. (1996) Productivity and the density of economic activity. American Economic Review, 86, 54-70.

CICCONE, A. (2002) Agglomeration effects in Europe. European Economic Review, 46, 213-227. CINGANO, F. \& SCHIVARDI, F. (2004) Identifying the sources of local productivity growth. Journal of the European Economic Association, 2, 720-742.

COMBES, P.-P., DURANTON, G. \& GOBILLON, L. (2008a) Spatial wage disparities: sorting matters! Journal of Urban Economics, 63, 723-742.

COMBES, P.-P., DURANTON, G., GOBILLON, L. \& ROUX, S. (2008b) Estimating agglomeration economies with history, geology, and worker effects. CEPR Discussion Papers 6728. DAVIS, D. R. \& WEINSTEIN, D. E. (2001) Market size, linkages, and productivity: a study of Japanese regions. NBER Working Paper 8518.

FINGLETON, B. (2003) Increasing returns: evidence from local wage rates in Great Britain. Oxford Economic Papers, 55, 716.

FINGLETON, B. (2006) The New Economic Geography versus Urban Economics: an evaluation using local wage rates in Great Britain. Oxford Econonomic Papers, 58, 501-530.

GRAHAM, D. J. (2000) Spatial variation in labour productivity in British manufacturing. International Review of Applied Economics, 14, 323. 
GRAHAM, D. J. (2005) Transport investment, agglomeration and urban productivity. Imperial College of London.

GRAHAM, D. J. (2007a) Agglomeration, productivity and transport investment. Journal of Transport Economics and Policy, 41(3), 317-343.

GRAHAM, D. J. (2007b) Identifying urbanization and localization externalities in manufacturing and service industries. Papers in Regional Science, (in press).

GRAHAM, D. J. (2007c) Variable returns to urbanization and the effect of road traffic congestion. Journal of Urban Economics, 62, 103-120.

GRAHAM, D. J. \& KIM, H. Y. (2008) An empirical analytical framework for agglomeration economies. Annals of Regional Science, 42, 267-289.

HENDERSON, J. V. (1986) Efficiency of resource usage and city size. Journal of Urban Economics, 19, 47-70.

HENDERSON, J. V. (2003) Marshall's scale economies. Journal of Urban Economics, 53, 1-28.

KANEMOTO, Y., OHKAWARA, T. \& SUZUKI, T. (1996) Agglomeration economies and a test for optimal city sizes in Japan. Journal of the Japanese and International Economies, 10, 379-398.

LALL, S. V., SHALIZI, Z. \& DEICHMANN, U. (2004) Agglomeration economies and productivity in Indian industry. Journal of Development Economics, 73, 643-673.

MION, G. \& NATICCHIONI, P. (2005) Urbanization externalities, market potential and spatial sorting of skills and firms. CEPR Discussion Papers 5172.

MOOMAW, R. L. (1981) Productivity and city size: a critique of the evidence. The Quarterly Journal of Economics, 96, 675.

MOOMAW, R. L. (1983a) Is population scale a worthless surrogate for business agglomeration economies. Regional Science and Urban Economics, 13.

MOOMAW, R. L. (1985) Firm location and city size: reduced productivity advantages as a factor in the decline of manufacturing in urban areas. Journal of Urban Economics, 17, 73-89. 
NAKAMURA, R. (1985) Agglomeration economies in urban manufacturing industries: a case of Japanese cities. Journal of Urban Economics, 17, 108-124.

RICE, P., VENABLES, A. J. \& PATACCHINI, E. (2006) Spatial determinants of productivity: analysis for the regions of Great Britain. Regional Science and Urban Economics, 36, 727-752.

ROSENTHAL, S. S. \& STRANGE, W. C. (2008) The attenuation of human capital spillovers. Journal of Urban Economics, In Press, Corrected Proof.

SVEIKAUSKAS, L., GOWDY, J. \& FUNK, M. (1988) Urban productivity: city size or industry size? Journal of Regional Science, 28, 185-202.

SVEIKAUSKAS, L. (1975) The productivity of cities. The Quarterly Journal of Economics, 89, 393.

TABUCHI, T. (1986) Urban agglomeration, capital augmenting technology, and labor market equilibrium. Journal of Urban Economics, 20, 211.

WHEELER, C. H. (2001) Search, sorting, and urban agglomeration. Journal of Labor Economics, 19, 879.

\section{References}

ASHENFELTER, O., HARMON, C. \& OOSTERBEEK, H. (1999) A review of estimates of the schooling/earnings relationship, with tests for publication bias. Labour Economics, Volume 6, Issue 4, 453-470.

BOM, P. R. D. \& LIGTHART, J. E. (2007) How productive is public capital? A meta-analysis. CESifo Working Paper, forthcoming. CESifo Working Paper, forthcoming.

BRIANT, A., COMBES, P. P. \& LAFOURCADE, M. (2008) Dots to boxes: do the size and shape of spatial units jeopardize economic geography estimations?, CEPR Discussion Paper no. 6928.

BUTTON, K. J. (1998) Infrastructure investment, endogenous growth and economic convergence. The Annals of Regional Science, 32, 145-162.

CARD, D. \& KRUEGER, A. B. (1995) Time-series minimum-wage studies: a meta-analysis. The American Economic Review, Vol. 85, No. 2, 238-243. 
DE GROOT, H. L., ABREU, M. \& FLORAX, R. J. G. M. (2005) A meta analysis of the effect of common currencies on international trade. Journal of Economic Surveys, 19, 389-420.

DISDIER, A.-C. \& HEAD, K. (2008) The puzzling persistence of the distance effect on bilateral trade. The Review of Economics and Statistics, 90(1), 37-48.

DURANTON, G. \& PUGA , D. (2000) Diversity and specialisation in Cities: Why, Where and When Does it Matter? Urban Studies, 37, 533.

EBERTS, R. W. \& MCMILLEN, D. P. (1999) Agglomeration economies and urban public infrastructure. Handbook of Regional and Urban Economics. Elsevier Science B.V.

FLORAX, R. J. C. M. (2001) Methodological Pitfalls in Meta-Analysis: Publication Bias. Research Memorandum 2001-28, Free University Amsterdam.

FLORAX, R. J. C. M. (2002) Accounting for Dependence Among Study Results in Meta-Analysis: Methodology and Applications to the Valuation and Use of Natura1 Resources. Research Memorandum 2002, 5. Free University, Amsterdam.

FUJITA, M. M., KRUGMAN, P. \& VENABLES, A. J. (1999) The spatial economy-cities, regions and international trade, Cambridge, Massachusetts, London, England, The MIT Press.

FUJITA, M. M. \& THISSE, J.-F. (2002) Economics of agglomeration-cities, industrial location and regional growth, Cambridge University.

GASPAR, J. \& GLAESER, E. L. (1998) Information technology and the future of cities. Journal of Urban Economics, 43, 136-156.

GERKING, S. (1994) Measuring productivity growth in U.S. regions: a survey. International Regional Science Review, 16, 155-185.

GLAESER, E. L. \& KOHLHASE, J. E. (2004) Cities, regions and the decline of transport costs. Papers in Regional Science, 83, 197-228.

GORG, H. \& STROBL, E. (2001) Multinational Companies and Productivity Spillovers: A MetaAnalysis. The Economic Journal, 111(475), 723-739. 
GRILICHES, Z. \& MAIRESSE, J. (1995) Production functions: the search for identification. NBER Working Papers 5067, National Bureau of Economic Research, Inc.

JEPPESEN, T., LIST, J. A. \& FOLMER, H. (2002) Environmental regulations and new plant location decisions: evidence from a meta-analysis. Journal of Regional Science, 42, 19-49.

KNELL, M. \& STIX, H. (2005) The income elasticity of money demand: a meta analysis of empirical results. Journal of Economic Surveys, 19, 513-533.

KOETSE, M. J., FLORAX, R. J. C. M. \& DE GROOT, H. L. (2007) The impact of effect size heterogeneity on meta-analysis: a Monte Carlo experiment. Tinbergen Institute Discussion Paper. TI 2007-052/3.

LONGHI, S., NIJKAMP, P. \& POOT, J. (2005) A meta analytic assessment of the effect of immigration on wages. Journal of Economic Surveys, 19, 451-477.

MINCER, J. (1974) Schooling, experience, and earnings, New York, Columbia University Press.

MOOMAW, R. L. (1983b) Spatial productivity variations in manufacturing: a critical survey of cross-sectional analyses. International Regional Science Review, 8, 1-22.

NIJKAMP, P. \& POOT, J. (2005) The last word on the wage curve? Journal of Economic Surveys, 19, 421-450.

NITSCH, V. (2005) Zipf zipped. Journal of Urban Economics, 57, 86-100.

ROSE, A. K. \& STANLEY, T. D. (2005) A meta analysis of the effect of common currencies on international trade. Journal of Economic Surveys, 19, 347-365.

ROSENTHAL, S. S. \& STRANGE, W. C. (2004) Evidence on the nature and sources of agglomeration economies. IN HENDERSON, J. V. \& THISSE, J. F. (Eds.) Handbook of Urban and Regional Economics, Vol.4. Amsterdam, Elsevier.

SHEFER, D. (1988) The effect of various means of communication on the operation and location of high-technology industries. IN GIAOUTZI, M. \& NIJKAMP, P. (Eds.) Informatics, High-Tech and Regional Development. Avebury, Aldershot, UK. 
SHEFER, D. \& BAR-EL, E. L. (1993) High technology industries as a vehicle for regional growth The Israel's peripheral regions. Environment \& Planning C, 11, 245-261.

STANLEY, T. D. (1998) New wine in old bottles: a meta-analysis of Ricardian equivalence. Southern Economic Journal, 64,3, 713-727.

STANLEY, T. D. (2001) Wheat from chaff: meta-analysis as quantitative literature review. The Journal of Economic Perspectives, 15, 131-150.

STANLEY, T. D. (2005) Beyond publication bias. Journal of Economic Surveys, 19, 309-345.

STANLEY, T. D. \& JARRELL, S. B. (2005) Meta Regression Analysis: A Quantitative Method of Literature Surveys. Journal of Economic Surveys, 19, 299-308.

VENABLES, T. (2007) Evaluating urban transport improvements: cost benefit analysis in the presence of agglomeration and income taxation. Journal of Transport Economics and Policy, 41, 173-188.

WEICHSELBAUMER, D. \& WINTER-EBMER, R. (2005) A meta analysis of the international gender wage gap. Journal of Economic Surveys, 19, 479-511.

WIESER, R. (2005) Research and development productivity and spillovers: empirical evidence at the firm level. Journal of Economic Surveys, 19, 587-621. 
Table 1: Papers included in the meta-analysis

\begin{tabular}{|c|c|c|c|c|c|c|c|c|}
\hline Study & Journal & Obs. & $\begin{array}{l}\text { Share } \\
(\%)\end{array}$ & Time Period & Data & Economic Sector & Mean & Range \\
\hline Aberg (1973) & $\begin{array}{l}\text { Regional and Urban } \\
\text { Economics }\end{array}$ & 4 & 0.55 & $\begin{array}{c}1965 ; 1967 ; 1968 \\
1965 / 1968\end{array}$ & CS,PD & Manufacturing & 0.017 & {$[0.014 ; 0.019]$} \\
\hline Au and Henderson (2006) & $\begin{array}{l}\text { Review of Economic } \\
\text { Studies }\end{array}$ & 2 & 0.27 & 1997 & CS & Economy & 0.013 & {$[-0.007 ; 0.033]$} \\
\hline Baldwin et al. (2007) & $\begin{array}{l}\text { Economic Analysis } \\
\text { research Paper Series }\end{array}$ & 8 & 1.10 & 1999 & CS & Manufacturing & 0.061 & {$[-0.008 ; 0.104]$} \\
\hline Baldwin et al. (2008) & $\begin{array}{l}\text { Economic Analysis } \\
\text { research Paper Series }\end{array}$ & 6 & 0.82 & $\begin{array}{c}\text { 1989-1999 } \\
\text { (change) }\end{array}$ & $\mathrm{PD}$ & Manufacturing & -0.088 & {$[-0.310 ; 0.300]$} \\
\hline Brulhart and Mathys (2008) & $\begin{array}{l}\text { Regional Science and } \\
\text { Urban economics }\end{array}$ & 14 & 1.92 & $\begin{array}{c}\text { 1980-2003 } \\
\text { (3 year averages) }\end{array}$ & $\mathrm{PD}$ & Economy;Manufacturing;Services & -0.080 & {$[-0.800 ; 0.280]$} \\
\hline Ciccone (2002) & $\begin{array}{l}\text { European Economic } \\
\text { Review }\end{array}$ & 7 & 0.96 & 1992 & CS & Economy (Non-agricultural) & 0.047 & {$[0.044 ; 0.051]$} \\
\hline Ciccone and Hall (1996) & $\begin{array}{l}\text { American Economic } \\
\text { Review }\end{array}$ & 8 & 1.10 & 1988 & CS & Economy (Non-agricultural) & 0.053 & {$[0.035 ; 0.084]$} \\
\hline Cingano and Shivardi (2004) & $\begin{array}{l}\text { Journal of the European } \\
\text { Economic Association }\end{array}$ & 13 & 1.78 & $\begin{array}{l}\text { 1986-1998 } \\
\text { (change) }\end{array}$ & CS & Manufacturing & 0.054 & {$[0.019 ; 0.073]$} \\
\hline Combes et al. (2008a) & $\begin{array}{l}\text { Journal of Urban } \\
\text { Economics }\end{array}$ & 11 & 1.51 & $\begin{array}{c}1976-96 \\
\text { (4 year intervals) }\end{array}$ & PD & Manufacturing; Services & 0.052 & {$[0.024 ; 0.143]$} \\
\hline Combes et al. (2008b) & CEPR discussion paper & 43 & 5.90 & $\begin{array}{c}1976-96 \\
\text { (4 year intervals) }\end{array}$ & $\mathrm{PD}$ & Manufacturing; Services & 0.035 & {$[0.012 ; 0.054]$} \\
\hline Davis and Weinstein (2001) & NBER working paper & 11 & 1.51 & 1985 & CS & Economy (Non-agricultural) & 0.027 & {$[0.010 ; 0.057]$} \\
\hline Fingleton (2003) & $\begin{array}{l}\text { Oxford Economic } \\
\text { Papers }\end{array}$ & 3 & 0.41 & $1999 ; 2000$ & CS & Economy & 0.017 & {$[0.016 ; 0.018]$} \\
\hline Fingleton (2006) & $\begin{array}{l}\text { Oxford Economic } \\
\text { Papers }\end{array}$ & 7 & 0.96 & 2000 & CS & Economy & 0.025 & [0.014;0.049] \\
\hline Graham (2000) & $\begin{array}{l}\text { International Review of } \\
\text { Applied Economics }\end{array}$ & 22 & 3.02 & $1984 ; 1991$ & CS & Manufacturing & -0.006 & {$[-0.168 ; 0.141]$} \\
\hline Graham (2005) & Working paper & 36 & 4.94 & $1995-2002$ & $\mathrm{PD}$ & Manufacturing; Services & 0.193 & {$[-0.037 ; 0.503]$} \\
\hline Graham (2007a) & $\begin{array}{l}\text { Journal of Transport } \\
\text { Economics Policy }\end{array}$ & 28 & 3.84 & 1995-2002 & $\mathrm{PD}$ & Manufacturing; Services & 0.110 & {$[-0.191 ; 0.382]$} \\
\hline Graham (2007b) & $\begin{array}{l}\text { Papers in Regional } \\
\text { Science }\end{array}$ & 108 & 14.81 & 1995-2002 & PD & Manufacturing; Services & 0.097 & {$[-0.277 ; 0.491]$} \\
\hline
\end{tabular}




\begin{tabular}{|c|c|c|c|c|c|c|c|c|}
\hline Study & Journal & Obs. & $\begin{array}{c}\text { Share } \\
(\%)\end{array}$ & Time Period & Data & Economic Sector & Mean & Range \\
\hline Graham and Kim (2008) & $\begin{array}{l}\text { Annals of Regional } \\
\text { Science }\end{array}$ & 18 & 2.47 & 1995-2002 & PD & Manufacturing; Services & 0.079 & {$[-0.130 ; 0.306]$} \\
\hline Graham (2007c) & $\begin{array}{l}\text { Journal of Urban } \\
\text { Economics }\end{array}$ & 18 & 2.47 & 1995-2002 & PD & Manufacturing; Services & 0.194 & {$[0.041 ; 0.399]$} \\
\hline Henderson (1986) & $\begin{array}{l}\text { Journal of Urban } \\
\text { Economics }\end{array}$ & 52 & 7.13 & $1970 ; 1972$ & CS & Manufacturing & 0.010 & {$[-0.366 ; 0.180]$} \\
\hline Henderson (2003) & $\begin{array}{l}\text { Journal of Urban } \\
\text { Economics }\end{array}$ & 4 & 0.55 & 1972-1992 & $\mathrm{PD}$ & Manufacturing & 0.024 & {$[-0.127 ; 0.189]$} \\
\hline Kanemoto et al. (1996) & $\begin{array}{l}\text { Journal of the Japanese } \\
\text { and International } \\
\text { Economies }\end{array}$ & 9 & 1.23 & 1985 & CS & Economy & 0.089 & {$[0.010 ; 0.250]$} \\
\hline Lall et al. (2004) & $\begin{array}{l}\text { Journal of Development } \\
\text { Economics }\end{array}$ & 18 & 2.47 & 1991 & CS & Manufacturing & 0.017 & {$[-0.204 ; 0.658]$} \\
\hline Mion and Naticchioni (2005) & CEPR discussion paper & 30 & 4.12 & 1991-1998 & $\mathrm{PD}$ & $\begin{array}{c}\text { Economy (Non-agricultural); } \\
\text { Manufacturing }\end{array}$ & 0.034 & {$[0.002 ; 0.109]$} \\
\hline Moomaw (1981) & $\begin{array}{l}\text { The Quarterly Journal } \\
\text { of Economics }\end{array}$ & 18 & 2.47 & 1967 & CS & Manufacturing & 0.060 & {$[0.006 ; 0.319]$} \\
\hline Moomaw (1983a) & $\begin{array}{l}\text { Regional Science and } \\
\text { Urban Economics }\end{array}$ & 26 & 3.57 & 1977 & CS & Manufacturing & 0.038 & {$[-0.052 ; 0.182]$} \\
\hline Moomaw (1985) & $\begin{array}{l}\text { Journal of Urban } \\
\text { Economics }\end{array}$ & 36 & 4.94 & $1967 / 1977$ & $\mathrm{PD}$ & Manufacturing & 0.040 & {$[-0.104 ; 0.270]$} \\
\hline Nakamura (1985) & $\begin{array}{l}\text { Journal of Urban } \\
\text { Economics }\end{array}$ & 38 & 5.21 & 1979 & CS & Manufacturing & 0.026 & {$[-0.037 ; 0.081]$} \\
\hline Rice et al. (2006) & $\begin{array}{l}\text { Regional Science and } \\
\text { Urban Economics }\end{array}$ & 14 & 1.92 & $\begin{array}{c}\text { 1998-2001 } \\
\text { (average) }\end{array}$ & CS & Economy & 0.025 & {$[-0.005 ; 0.070]$} \\
\hline Rosenthal and Strange (2008) & $\begin{array}{l}\text { Journal of Urban } \\
\text { Economics }\end{array}$ & 9 & 1.23 & 2000 & CS & Economy & 0.042 & {$[0.025 ; 0.058]$} \\
\hline Sveikauskas (1975) & $\begin{array}{l}\text { The Quarterly Journal } \\
\text { of Economics }\end{array}$ & 6 & 0.82 & 1967 & CS & Manufacturing & 0.057 & {$[0.012 ; 0124]$} \\
\hline Sveikauskas et al. (1988) & $\begin{array}{l}\text { Journal of Regional } \\
\text { Science }\end{array}$ & 42 & 5.76 & 1977 & CS & Manufacturing & 0.013 & {$[0.007 ; 0.017]$} \\
\hline Tabucchi (1986) & $\begin{array}{l}\text { Journal of Urban } \\
\text { Economics }\end{array}$ & 57 & 7.82 & 1980 & CS & Manufacturing & 0.060 & {$[-0.079 ; 0.300]$} \\
\hline Wheeler (2001) & $\begin{array}{l}\text { Journal of Labor } \\
\text { Economics }\end{array}$ & 3 & 0.41 & 1980 & CS & Economy & 0.017 & {$[0.000 ; 0.030]$} \\
\hline
\end{tabular}

CS: cross-sectional data, PD: panel data. 
Table 2: Some summary statistics of the meta-sample

\begin{tabular}{|c|c|c|c|c|c|c|c|}
\hline Sample & Obs. & $\%$ & Mean & Median & SD & Min & Max \\
\hline Estimates & 729 & 100 & 0.058 & 0.041 & 0.115 & -0.800 & 0.658 \\
\hline Studies & 34 & 100 & 0.043 & 0.037 & 0.055 & -0.088 & 0.194 \\
\hline \multicolumn{8}{|l|}{ by country/region } \\
\hline Brazil & 20 & 2.74 & 0.046 & 0.024 & 0.052 & 0.003 & 0.180 \\
\hline Canada & 14 & 1.92 & -0.003 & 0.028 & 0.151 & -0.310 & 0.300 \\
\hline China & 2 & 0.27 & 0.013 & 0.013 & 0.028 & -0.007 & 0.033 \\
\hline Europe & 21 & 2.88 & -0.038 & 0.045 & 0.258 & -0.800 & 0.280 \\
\hline France & 54 & 7.41 & 0.039 & 0.035 & 0.022 & 0.012 & 0.143 \\
\hline India & 18 & 2.47 & 0.017 & 0.007 & 0.179 & -0.204 & 0.658 \\
\hline Italy & 43 & 5.90 & 0.041 & 0.031 & 0.032 & 0.002 & 0.109 \\
\hline Japan & 115 & 15.78 & 0.048 & 0.040 & 0.060 & -0.079 & 0.300 \\
\hline Sweden & 4 & 0.55 & 0.017 & 0.018 & 0.002 & 0.014 & 0.019 \\
\hline UK/GB & 254 & 34.84 & 0.102 & 0.083 & 0.145 & -0.277 & 0.503 \\
\hline $\begin{array}{r}\text { US } \\
\text { by measure of urban agglomeration }\end{array}$ & \multicolumn{6}{|c|}{ by measure of urban agglomeration } & 0.319 \\
\hline Market potential/Distance band & 279 & 38.27 & 0.101 & 0.076 & 0.143 & -0.277 & 0.658 \\
\hline Density & 158 & 21.67 & 0.030 & 0.039 & 0.099 & -0.800 & 0.300 \\
\hline Size & 292 & 40.05 & 0.032 & 0.030 & 0.076 & -0.410 & 0.319 \\
\hline \multicolumn{8}{|l|}{ by type of response variable } \\
\hline Labor productivity & 342 & 46.91 & 0.053 & 0.038 & 0.095 & -0.366 & 0.503 \\
\hline Output & 264 & 36.21 & 0.076 & 0.057 & 0.156 & -0.800 & 0.658 \\
\hline Wages & 123 & 16.87 & 0.034 & 0.032 & 0.030 & -0.096 & 0.143 \\
\hline \multicolumn{8}{|l|}{ by industry group } \\
\hline Economy & 168 & 23.05 & 0.031 & 0.034 & 0.099 & -0.800 & 0.250 \\
\hline Manufacturing & 427 & 58.57 & 0.040 & 0.036 & 0.095 & -0.366 & 0.658 \\
\hline Services & 134 & 18.38 & 0.148 & 0.142 & 0.148 & -0.219 & 0.503 \\
\hline
\end{tabular}

Figure 1: Distribution of the elasticity estimates over the time period of the study (midpoint)

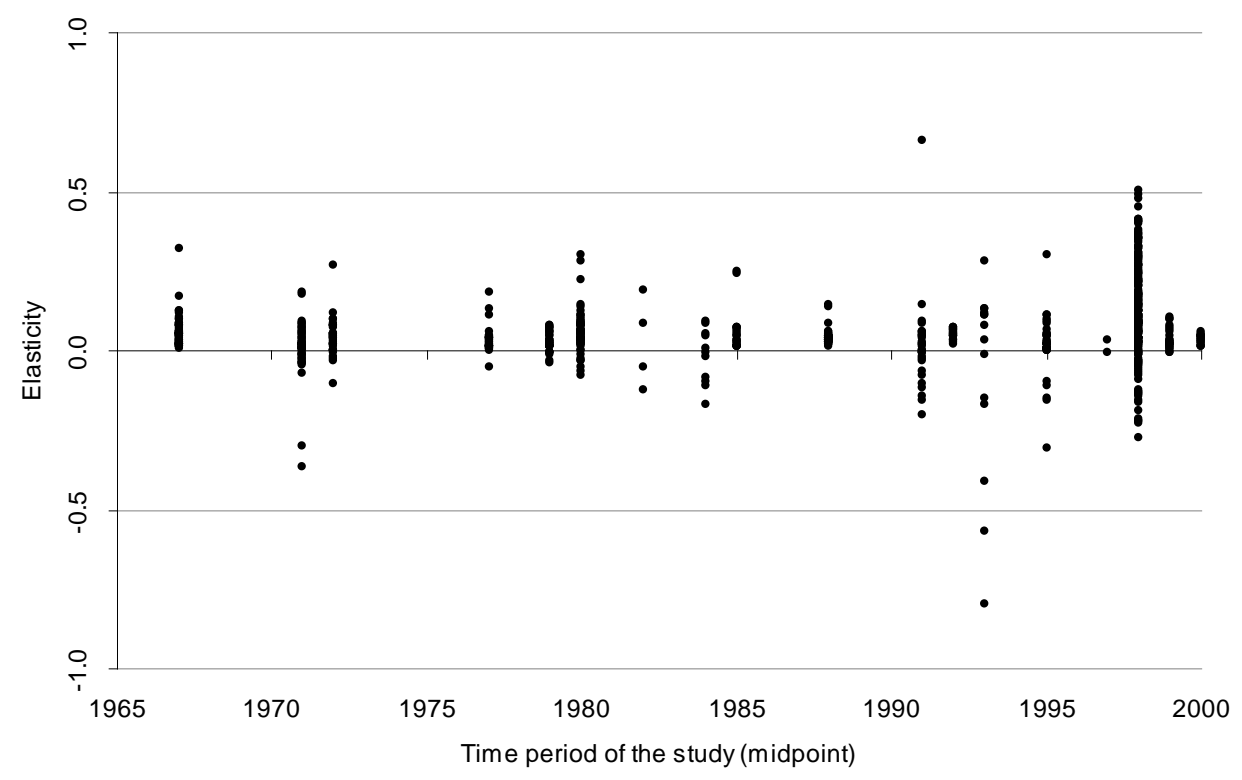


Table 3: Meta-Explanatory variables

\begin{tabular}{|c|c|c|c|}
\hline Empirical dimension & Variable & Definition & Reference case \\
\hline \multirow[t]{3}{*}{ Time period of the analysis } & $\mathrm{D}_{70-79}$ & 1 if study period is between 1970 and 1979,0 otherwise & Study uses data for years before 1970 \\
\hline & $\mathrm{D}_{80-89}$ & 1 if study period is between 1980 and 1989,0 otherwise & (between 1960 and 1969) \\
\hline & $\mathrm{D}_{>90}$ & 1 if study period is after 1990,0 otherwise & \\
\hline \multirow[t]{2}{*}{ Country/continent } & $\mathrm{D}_{\text {Country i }}$ & 1 if study is applied to country $i$ & i) Estimates are for the US \\
\hline & $\mathrm{D}_{\text {Continent } \mathrm{i}}$ & 1 if study is applied to continent $i$ & ii) Estimates are for Europe \\
\hline \multirow[t]{2}{*}{ Coverage of economy } & $\mathrm{D}_{\mathrm{SER}}$ & 1 if service industry, 0 otherwise & Study uses data for the entire economy/non-agricultural \\
\hline & $\mathrm{D}_{\text {MAN }}$ & 1 if manufacturing, 0 otherwise & economy \\
\hline \multirow[t]{2}{*}{ Data } & $\mathrm{D}_{\mathrm{PD}}$ & 1 if study uses panel data, 0 otherwise & Study uses cross-sectional data \\
\hline & $\mathrm{D}_{\mathrm{IND}}$ & 1 if firm/worker level data, 0 otherwise & Study uses data aggregated at some regional level \\
\hline Type of geographic units & $\mathrm{D}_{\mathrm{GEO}}$ & 1 if the study uses economically meaningful boundaries, 0 otherwise & Study uses administrative boundaries \\
\hline \multirow{2}{*}{ Estimation method } & $\mathrm{D}_{\text {HET_CS }}$ & 1 if study uses fixed-effects for cross-sectional units, 0 otherwise & Study does not use fixed-effects \\
\hline & $\mathrm{D}_{\mathrm{IV}}$ & 1 if study uses IV estimators, 0 otherwise & $\begin{array}{l}\text { Study does not correct for reverse causality between } \\
\text { productivity-agglomeration }\end{array}$ \\
\hline \multirow[t]{2}{*}{ Definition of urbanization } & $\mathrm{D}_{\text {DENS }}$ & 1 if employment density, 0 otherwise & Study defines urban agglomeration by total \\
\hline & $\mathrm{D}_{\mathrm{MP}}$ & 1 if market potential type/distance band, 0 otherwise & population/employment \\
\hline \multirow[t]{2}{*}{ Specification of agglomeration economies } & $\mathrm{D}_{\mathrm{LOC}}$ & $\begin{array}{l}1 \text { if there is a measure of localization economies together with } \\
\text { urbanization economies, } 0 \text { otherwise }\end{array}$ & $\begin{array}{l}\text { Study does not include a measure of localization } \\
\text { economies }\end{array}$ \\
\hline & $\mathrm{D}_{\mathrm{HCAP}}$ & 1 if there are controls for differences in human capital & Study does not control for differences in human capital \\
\hline \multirow[t]{2}{*}{ Dependent variable } & $\mathrm{D}_{\mathrm{W}}$ & 1 if wage, 0 otherwise & Dependent variable of the study is total output \\
\hline & $\mathrm{D}_{\mathrm{LP}}$ & 1 if labor productivity, 0 otherwise & \\
\hline
\end{tabular}


Table 4: Meta-regressions results

\begin{tabular}{|c|c|c|c|c|c|c|c|c|c|c|c|c|c|c|c|c|c|}
\hline \multirow{2}{*}{$\begin{array}{l}\text { Samples } \\
\text { Estimators }\end{array}$} & & \multicolumn{2}{|l|}{$(1)$} & \multicolumn{2}{|l|}{$(2)$} & \multicolumn{2}{|l|}{ (3) } & \multicolumn{2}{|l|}{$(4)$} & \multicolumn{2}{|l|}{ (5) } & \multicolumn{2}{|l|}{$(6)$} & \multicolumn{2}{|l|}{$(7)$} & \multicolumn{2}{|l|}{ (8) } \\
\hline & & \multicolumn{2}{|l|}{ OLS } & \multicolumn{2}{|c|}{ GLS-RE } & \multicolumn{2}{|l|}{ OLS } & \multicolumn{2}{|c|}{ GLS-RE } & \multicolumn{2}{|l|}{ OLS } & \multicolumn{2}{|c|}{ GLS-RE } & \multicolumn{2}{|l|}{ OLS } & \multicolumn{2}{|c|}{ GLS-RE } \\
\hline \multirow[t]{2}{*}{$\varepsilon$} & Constant & 0.1285 & & 0.1218 & & 0.0773 & & 0.0699 & & 0.1641 & & 0.157 & & 0.0839 & & 0.0718 & \\
\hline & & $(0.0313)$ & $* * *$ & $(0.0447)$ & $* * *$ & $(0.0293)$ & $* * *$ & $(0.0341)$ & $* *$ & $(0.0397)$ & $* * *$ & $(0.0577)$ & $* * *$ & $(0.0348)$ & $* *$ & $(0.0413)$ & * \\
\hline \multirow[t]{2}{*}{$\mathrm{D}_{70-79}$} & Time period of analysis is between 1970 and 1979 & -0.0439 & & -0.0403 & & -0.0302 & & -0.0249 & & -0.0397 & & -0.0471 & & -0.0166 & & -0.0038 & \\
\hline & & $(0.0181)$ & $* *$ & $(0.0116)$ & $* * *$ & $(0.0183)$ & * & $(0.0223)$ & & $(0.0230)$ & * & $(0.0240)$ & * & $(0.0227)$ & & $(0.0282)$ & \\
\hline \multirow[t]{2}{*}{$\mathrm{D}_{80-89}$} & Time period of analysis is between 1980 and 1989 & -0.0145 & & -0.0143 & & -0.0183 & & -0.0001 & & -0.0113 & & -0.0204 & & 0.004 & & 0.0323 & \\
\hline & & $(0.0193)$ & & $(0.0153)$ & & $(0.0195)$ & & $(0.0281)$ & & $(0.0362)$ & & $(0.0356)$ & & $(0.0274)$ & & $(0.0381)$ & \\
\hline \multirow[t]{2}{*}{$\mathrm{D}_{>90}$} & Time period of analysis is after 1990 & -0.0015 & & -0.0062 & & -0.025 & & -0.014 & & -0.0226 & & -0.012 & & -0.025 & & -0.0074 & \\
\hline & & $(0.0278)$ & & $(0.0307)$ & & $(0.0180)$ & & $(0.0241)$ & & $(0.0792)$ & & $(0.0803)$ & & $(0.0200)$ & & $(0.0287)$ & \\
\hline \multirow[t]{2}{*}{$\mathrm{D}_{\mathrm{BR}}$} & Study is applied to Brazil & 0.019 & & 0.0269 & & & & & & -0.0442 & & -0.042 & & & & & \\
\hline & & $(0.0265)$ & & $(0.0252)$ & & & & & & $(0.0420)$ & & $(0.0395)$ & & & & & \\
\hline $\mathrm{D}_{\mathrm{CA}}$ & Study is applied to Canada & -0.0368 & & -0.0294 & & & & & & -0.0606 & & -0.0757 & & & & & \\
\hline & & $(0.0416)$ & & $(0.0486)$ & & & & & & $(0.0897)$ & & $(0.0723)$ & & & & & \\
\hline $\mathrm{D}_{\mathrm{CH}}$ & Study is applied to China & -0.0736 & & -0.0588 & & & & & & -0.1031 & & -0.1064 & & & & & \\
\hline & & $(0.0365)$ & $* *$ & $(0.0316)$ & $*$ & & & & & $(0.0842)$ & & $(0.0696)$ & & & & & \\
\hline $\mathrm{D}_{\mathrm{FR}}$ & Study is applied to France & 0.1139 & & 0.1041 & & & & & & 0.0845 & & 0.0774 & & & & & \\
\hline $\mathrm{D}_{\mathrm{IN}}$ & Study is applied to India & -0.0144 & & -0.0151 & & & & & & -0.0923 & & -0.1282 & & & & & \\
\hline & & $(0.0509)$ & & $(0.0323)$ & & & & & & $(0.0810)$ & & $(0.0610)$ & $* *$ & & & & \\
\hline $\mathrm{D}_{\mathrm{IT}}$ & Study is applied to Italy & 0.0539 & & 0.0562 & & & & & & 0.1133 & & 0.0861 & & & & & \\
\hline & & $(0.0307)$ & $*$ & $(0.0361)$ & & & & & & $(0.0839)$ & & $(0.0856)$ & & & & & \\
\hline $\mathrm{D}_{\mathrm{JP}}$ & Study is applied to Japan & -0.0514 & & -0.0427 & & & & & & -0.109 & & -0.1039 & & & & & \\
\hline & & $(0.0278)$ & $*$ & $(0.0436)$ & & & & & & $(0.0470)$ & $* *$ & $(0.0653)$ & & & & & \\
\hline $\mathrm{D}_{\mathrm{SW}}$ & Study is applied to Sweden & -0.1318 & & -0.119 & & & & & & -0.1797 & & -0.173 & & & & & \\
\hline & & $(0.0338)$ & $* * *$ & $(0.0428)$ & $* * *$ & & & & & $(0.0552)$ & $* * *$ & $(0.0662)$ & $* * *$ & & & & \\
\hline $\mathrm{D}_{\mathrm{UK} / \mathrm{GB}}$ & Study is applied to the UK/GB & -0.0224 & & -0.0192 & & & & & & -0.1011 & & -0.1142 & & & & & \\
\hline & & $(0.0202)$ & & $(0.0246)$ & & & & & & $(0.0617)$ & & $(0.0615)$ & * & & & & \\
\hline $\mathrm{D}_{\text {Asia }}$ & Study uses data for country in Asia & & & & & -0.0106 & & -0.0129 & & & & & & -0.017 & & -0.0176 & \\
\hline & & & & & & $(0.0235)$ & & $(0.0184)$ & & & & & & $(0.0280)$ & & $(0.0233)$ & \\
\hline $\mathrm{D}_{\text {North America }}$ & Study uses data for country in North America & & & & & -0.0355 & & -0.0345 & & & & & & -0.0402 & & -0.0451 & \\
\hline & & & & & & $(0.0193)$ & $*$ & $(0.0277)$ & & & & & & $(0.0259)$ & & $(0.0350)$ & \\
\hline $\mathrm{D}_{\text {South America }}$ & Study uses data for country in South America & & & & & 0.0554 & & 0.0596 & & & & & & 0.0505 & & 0.0529 & \\
\hline & & & & & & $(0.0282)$ & $*$ & $(0.0295)$ & $* *$ & & & & & $(0.0368)$ & & $(0.0358)$ & \\
\hline
\end{tabular}




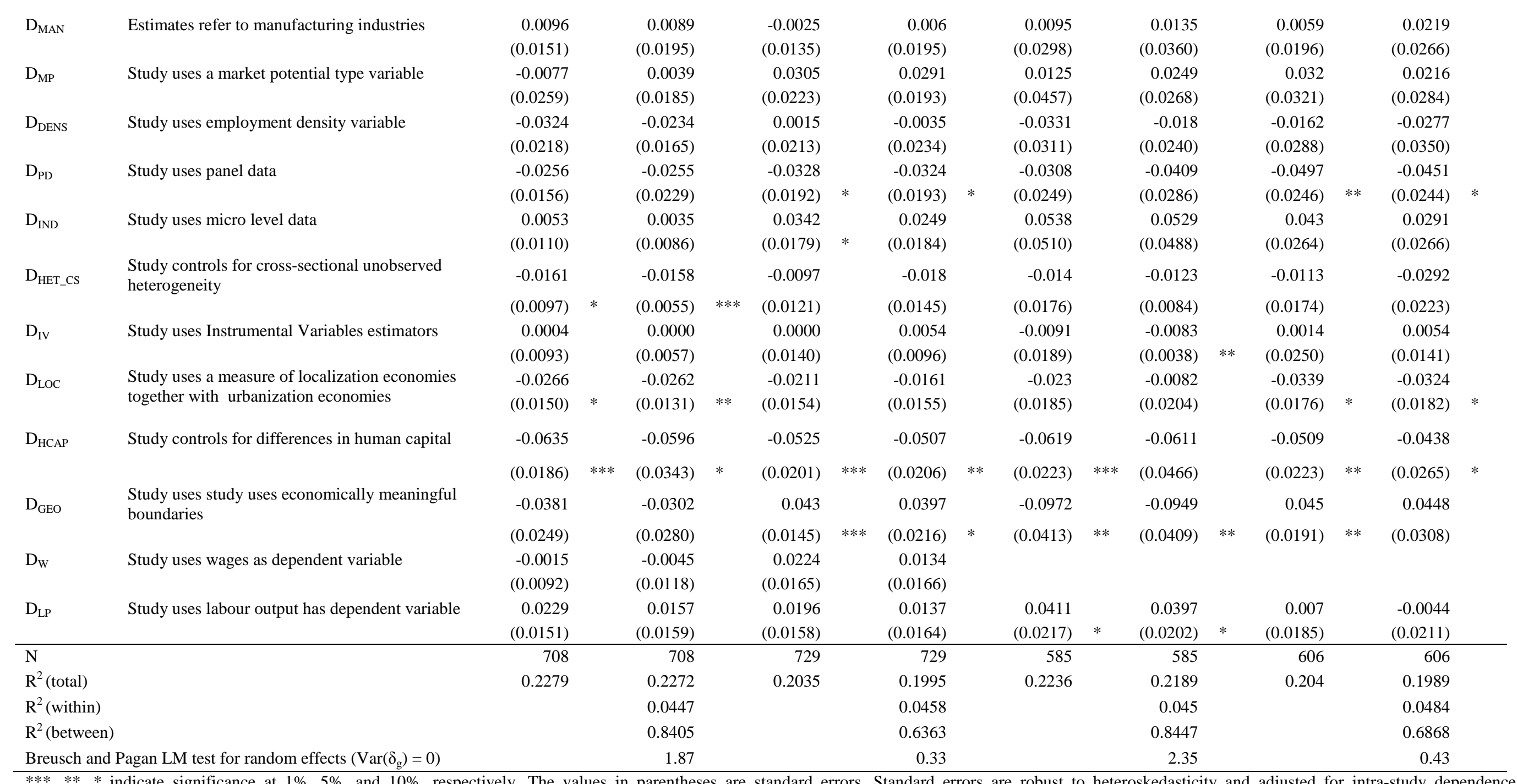


Figure 2: Association between the elasticity estimates and respective standard errors

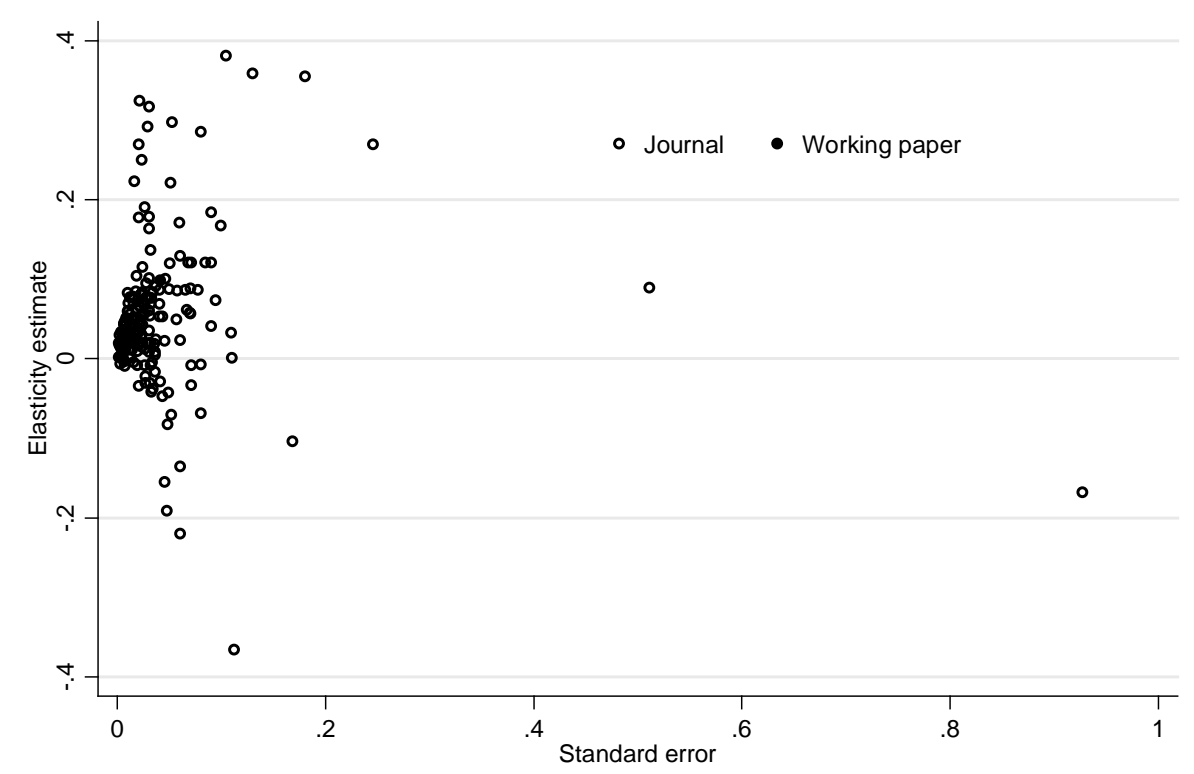

Figure 3: Association between the absolute value of the elasticity estimates and respective standard errors

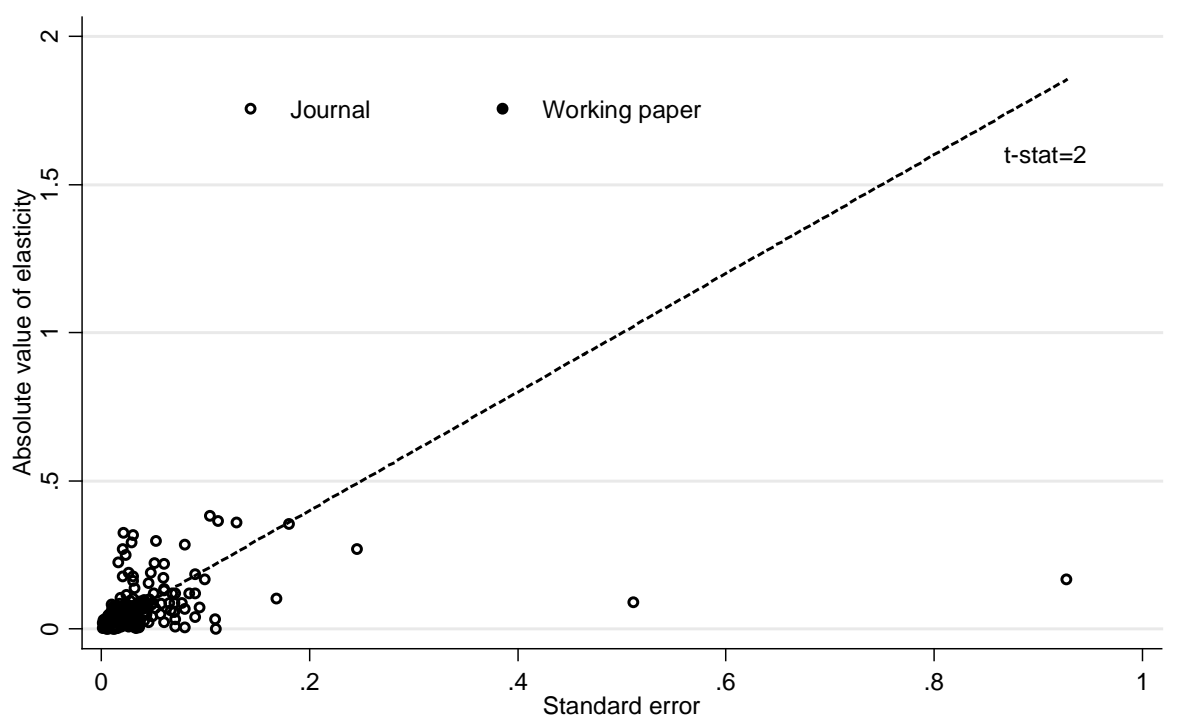


Table 5: Publication bias results

\begin{tabular}{|c|c|c|c|c|c|c|}
\hline Model & (1) & & (2) & & (3) & \\
\hline \multirow[t]{2}{*}{$\varepsilon$} & 0.055 & & 0.064 & & 0.039 & \\
\hline & $(0.0042)$ & $* * *$ & $(0.0038)$ & $* * *$ & $(0.0104)$ & $* * *$ \\
\hline \multirow[t]{2}{*}{$\alpha$} & -0.079 & & 0.218 & & & \\
\hline & $(0.1009)$ & & $(0.0927)$ & $* *$ & & \\
\hline \multirow[t]{2}{*}{$\alpha_{\mathrm{p}}$} & & & & & 0.592 & \\
\hline & & & & & $(0.3303)$ & * \\
\hline \multirow[t]{2}{*}{$\alpha_{n}$} & & & & & -0.351 & \\
\hline & & & & & $(0.1778)$ & $*$ \\
\hline$\alpha_{p}=-\alpha_{n}$ & & & & & 8.25 & $* * *$ \\
\hline $\mathrm{R}^{2}$ (total) & 0.0013 & & 0.0821 & & 0.2445 & \\
\hline $\mathrm{R}^{2}$ (between) & 0.0674 & & 0.2269 & & 0.3673 & \\
\hline $\mathrm{R}^{2}$ (within) & 0.0050 & & 0.0610 & & 0.1906 & \\
\hline $\mathrm{N}$ & 187 & & 187 & & 187 & \\
\hline
\end{tabular}

***, **, * indicate significance at $1 \%, 5 \%$, and $10 \%$, respectively. The values in parentheses are standard errors. Standard errors are robust to heteroskedasticity and adjusted for intra-study dependence. 